\title{
Variable Annuities and the New Retirement Realities*
}

\author{
Christopher M. Condron \\ AXA Financial, 1290 Avenue of the Americas, NY, NY 10104, USA. \\ E-mail: christopher.condron@axa-equitable.com
}

People today face the prospect of a retirement that may likely last 25 years or even longer. Concerns about the stock markets' volatility and the potential impact on their portfolios has caused many individuals approaching retirement to retreat from investments in equities and shift into fixed-income assets, despite historical evidence that investment in equities provide long-term returns superior to fixed-income returns. This conservative approach, embodied in such tools as Target Date Funds, for some investors could hamper asset accumulation and may make it less likely that assets will remain adequate to provide sustained sources of income during a lengthy retirement period. The insurance industry is uniquely positioned to offer those nearing retirement an alternative investment and risk management strategy through variable annuities. Features in the newer variable annuity product designs encourage individuals to remain invested in equities at older ages by cushioning them from some of the consequences of market volatility. As a result, investors are more apt to maintain a more equity-weighted investment portfolio and thereby have an opportunity to realize a greater portion of the superior growth potential that equities have historically provided over the long term.

The Geneva Papers (2008) 33, 12-32. doi:10.1057/palgrave.gpp.2510165

Keywords: variable annuities; retirement; equities; Target Date Funds

\section{The value of variable annuities}

The financial services industry is playing an increasingly crucial role in helping individuals around the world prepare for retirement. Individuals nearing retirement face a number of challenges. Among them is the increasing concern over traditional sources of retirement security as illustrated by the results of AXA's most recent Global Retirement Survey: ${ }^{1}$

- In Japan, 41 per cent of working respondents and 25 per cent of retired respondents feel that their social security system is in crisis.

- In Germany, 54 per cent of working respondents aged 45-54 and 66 per cent of respondents aged 35-44 do not think the official pension system will still exist when they are 75 .

\footnotetext{
* This paper is intended for informational purposes. It is not intended for public use or use in connection with the sale of any product. Customers should consult with their financial advisor before making a decision on an investment strategy and for specific legal, tax, investment and accounting advice.

${ }^{1}$ AXA Equitable (2007).
} 
- In the U.K., 49 per cent of working respondents aged 45-54 do not think the official pension system will still exist when they are 75 . The number rises to 54 per cent for working U.K. respondents aged 35-44.

- In China, 63 per cent of working respondents feel it is the individual's responsibility to provide for retirement income.

- In the U.S., 57 per cent of working respondents aged 45-54 and 66 per cent of respondents aged 35-44 do not think the official pension system will still exist when they are 75 .

At the same time, in many countries - and particularly in the U.S. - retirees have not accumulated nearly enough savings to maintain their pre-retirement standard of living for the duration of their retirement. According to Boston College's Center for Retirement Research, nearly 45 per cent of working households were at risk of falling short of the income needed to fund their standard of living in retirement. And, with medical advances continuing to extend life spans, the savings gap continues to grow. ${ }^{2}$

As individuals nearing retirement seek answers to the retirement savings challenges, the insurance industry is uniquely positioned to deliver an innovative solution that can help address asset accumulation shortages and asset distribution and longevity uncertainties. The package of benefits and features offered by newer variable annuity product designs can facilitate a more aggressive investment strategy than conventional wisdom previously deemed advisable. At the same time, newer variable annuity products can also ensure that investors derive an income stream from their savings that they cannot outlive.

Although there may be some risk for consumers to rely upon insurers' ability to fulfill these guarantees in the future, most insurance companies have developed hedging programs that replicate the Variable Annuity exposure, protecting the company against declines in the equity markets and interest rates. This, in turn, should give comfort to investors as to the viability of variable annuity products.

Indeed, it is these innovative features, particularly the newer guarantee features, that are primarily responsible for the growing popularity of variable annuities around the world. Those guarantees, which can include minimum death benefits, minimum income benefits (GMIBs), minimum withdrawal benefits (GMWBs) and minimum accumulation benefits and the protection they offer, help to explain why more than $\$ 1.35$ trillion is currently invested in variable annuities in the U.S., a 50 per cent increase over the last 5 years in a market where the product is already well established.

In Japan, where variable annuities were introduced more recently, their assets reached $\$ 100$ billion in just a few years. And, in part, because of the retirement concerns noted above, the market in such European countries as Germany is also growing rapidly. All told, by the end of 2007, AXA alone will offer variable annuities in 12 countries around the world, and many other insurance companies are active in the global market as well.

Sales of variable annuities are continuing to grow despite some lingering misconceptions. Among those misconceptions are that the product continues to be merely a tax-advantaged mutual fund, that investors forego access to their investment,

${ }^{2}$ Munnel et al. (2007). 
and that the product charges are excessive. While it is not the intention of this paper to engage in a detailed rebuttal to these or other objections, we would make the following observations. First, it is our experience that most variable annuities are being bought because of their asset accumulation opportunities, guaranteed minimum income, minimum death and minimum withdrawal benefits, not necessarily solely for their tax benefits. Second, variable annuities are investment portfolios that have liquidity, albeit often with some surrender (and possibly tax) penalties for a period after purchase, at any point prior to annuitization. Third, variable annuity fees pay for substantial additional benefits that are simply not available in other products.

That said, we have to recognize that variable annuities have not always enjoyed the best reputation in the market. In the U.S., this is due to a number of factors including, among others, the failure by some observers to appreciate that the value proposition offered by variable annuities has evolved substantially with the introduction of guaranteed living benefits a decade ago. Another contributing factor has been a tendency for traditional variable annuities to be confused with equity-indexed annuities, some of which carry exceptionally high commission levels and correspondingly high (and long duration) surrender penalties. Most equity-indexed annuities are not regulated by the U.S. Securities and Exchange Commissions or the Financial Industry Regulatory Authority and their sellers are not required to have a securities license. This has contributed to some widely publicized abuses, including allegations that large numbers of equity-indexed annuities have been sold to persons for whom they were not always suitable. Media coverage of such abuses has tended to omit or blur the clear distinctions between equity-indexed and traditional variable annuities, to the detriment of variable annuity issuers and agents.

Fortunately, the reputable players in the industry have established clear and stringent compliance rules, and have demonstrated intolerance for unethical sales practices. In addition, we in the industry have established tools for proactive consumer education, such as the web-based Variable Annuities Knowledge Center. ${ }^{3}$ In the wake of these efforts, we believe it is entirely appropriate for the insurance industry to vigorously promote the value that variable annuities can play in helping to address what many see as the looming global retirement security crisis.

\section{Coping with the changing face of retirement}

It is well established that prospective retirees, both in America and worldwide, are facing a number of demographic and economic challenges. In a trend driven largely by today's constant advances in health care, people are living longer, and are looking at likely retirement periods of 25-30 years or more. For example, in 1970, for an American couple aged 60 , the probability of at least one member living to at least age 90 was only 42 per cent. By 2000, that probability had grown to 62 per cent. ${ }^{4}$ While that's clearly a positive development, it places a strain on U.S. entitlement programs

\footnotetext{
${ }^{3}$ http://www.variableannuityfacts.org/index.cfm.

${ }^{4}$ Cherry (1971) and Johansen (1995-1996).
} 
(i.e., Social Security and Medicare) that will, if anything, become even greater as 77 million U.S. Baby Boomers retire. Meanwhile, traditional defined-benefit pensions are rapidly disappearing. In 1977, there were 115,000 U.S. corporations that offered defined-benefit plans to their employees; today, there are fewer than 30,000. Both in the U.S. and around the globe, people are losing confidence in traditionally defined pensions, as well as government-sponsored programs, as a source of retirement income.

At the same time, historical inflationary trends are widening the gap between the needs of retirees and traditional savings or 401(k) plans. Consider the fact that in 1977, the price of gasoline in the U.S. was 57 cents a gallon; today, it is in the $\$ 3$ per gallon range. In 1977 , the median price of a home in the U.S. was $\$ 42,600$; today, it is more than $\$ 180,000$. To keep pace with inflation, assets need to continue to grow.

Unfortunately, in our experience, much of what passes for retirement planning does not effectively address the longevity risks that today's retirees and pre-retirees face. Among other things, too many retirement plans are guided by conservative planning strategies that emphasize an allocation away from equities as investors approach retirement age. An unduly conservative strategy simply will not close the retirement savings gap for a large percentage of retirees and pre-retirees, nor will it enable them to keep up with pernicious effects of inflation over the long term. Many of these individuals need or want the option to pursue a more aggressive approach in an effort to increase their retirement nest eggs. That more aggressive approach typically entails an equity-oriented investment strategy.

The benefits of investing in equities are well established. Despite the ups and downs of the stock market, an investment in equities typically has yielded far better results than investment in fixed-income assets such as government bonds or treasury bills. A single dollar invested in small-company stocks at year-end 1925 would, at the historical average annual return of 12.7 per cent, have compounded by 2006 to $\$ 15,922$. By contrast, a dollar invested in U.S. government bonds would, at an average annual return of 5.4 per cent, have compounded to $\$ 72 .{ }^{5}$ Over the course of time it is our observation that the more heavily invested an individual is in equities, the more likely they are to experience better portfolio performance.

The challenge, of course, is that few investors are prepared or equipped to cope with the ups and downs of the equities markets during retirement, or even when they are close to retirement age. Investors who retired in 1981, 1990 or 2001-2003 would have immediately endured down years in their equity portfolio, as measured by the aggregate returns of the S\&P 500. Although these down years have been temporary and typically of smaller magnitude than equities' upside returns, they are nonetheless painful, cause asset depletion and investors seek to avoid them. Perhaps more importantly, when they occur in the distribution phase of an investor's life cycle - that

\footnotetext{
${ }^{5}$ For 1926-1981, the returns on small-company stocks are based on a portfolio of stocks represented by the fifth capitalization quintile of stocks on the New York Stock Exchange; from 1982 to March 2001, on the Dimensional Fund Advisors (DFA) Small Company 9/10 Fund and thereafter, on the DFA Micro Cap Fund. The returns on Government Bonds are based on 20-year U.S. Bonds.
} 
is, when an investor is "spending down" his/her savings - the effects can be fairly dramatic. Withdrawal amounts that seemed relatively modest during periods of strong market performance can rapidly deplete savings during market downturns.

\section{Market volatility brings out conservatism}

Fear of such downturns in the equities markets thus often causes investors to adopt a more conservative approach to retirement planning - one that gradually moves investors away from equities as they approach retirement age. One tool, which has been designed to support such a strategy, is the so-called Target Date Funds (TDFs). TDFs, which were introduced in 1996, have become an increasingly popular investment vehicle intended to manage the risk of equity investing by automatically rebalancing an investor's assets as he/she approaches retirement age. They shift either gradually or rapidly, depending on the time remaining until retirement - to fixed-income investments.

TDFs are a positive step in the right direction for retirement-minded investors, as they provide a strategy and structure for asset accumulation and offer more balance to these investments than investors typically chose in the past. However, TDFs create a more conservative asset allocation structure toward the target date which may not be sufficient to hedge inflation needs.

The use of TDFs has grown dramatically since 1996. According to Morningstar, Inc., by 2001, $\$ 11.6$ billion in net assets had been invested in TDFs in the U.S.; by 2007 , that figure had reached $\$ 128.7$ billion. One reason for TDFs' popularity is investors' perception that they offer a simple way to manage the risk of exposure to securities. These perceptions and corresponding risk-averse and reactive behavior have been researched and documented in several studies, which concluded that investors are not as well informed and may often make decisions that may not serve their own economic best interests. Consumers', or investors', propensity to expect excessive returns in exchange for limited risks, to disproportionately sacrifice asset appreciation in favor of asset protection and to fall prey to general investment inertia or deferral to the status quo, has led investors to allocate away from strategies that may offer more suitable risk management and better value, such as variable annuities.

TDFs, in essence, allow investors to "set it and forget it" - knowing that over time, as they approach retirement, their portfolios will be automatically rebalanced in the direction of fixed-income holdings. TDFs also address individuals' concerns about their ability to personally manage their own portfolios and respond to market fluctuations. And the growth of TDFs has further proliferated as companies include them in their 401(k) plans, which, in many cases, default investors into TDFs if they do not make alternative selections.

In summary, while TDFs may be an appropriate asset gathering tool for individuals who are looking for professional assistance in asset allocation as they build their nest eggs, they may not, however, be the optimal tools for pre-retirees and retirees looking to close a retirement savings gap much later in life and ensure that they will not outlive an income stream. The remainder of this paper will examine the relative merits of TDFs and variable annuities in coping with these challenges. 


\section{A side-by-side comparison}

Although past performance is not indication of future results, the availability of historical data permits us to compare these two investment vehicles to assess their benefits over various market cycles, in terms of both asset accumulation and sources of meaningful retirement income. We can use these data to help assess how investors nearing retirement would have fared in past years if they had stayed heavily invested in equities, even during retirement, using the variable annuity model of risk management-versus using the typical TDF approach of retreating from equities over time.

For this purpose, we conducted a 32-year side-by-side analysis of how either a 50- or 60 -year-old investor would have fared if, in 1975, they had had the option to invest in an aggressive asset allocation fund in a variable annuity with guaranteed lifetime income benefits, with a 15- or 5-year horizon until retirement, respectively, compared with a TDF with similar horizons - then seeing how their assets would have performed and satisfied their income needs in each case, if they had begun withdrawals from each of these vehicles at age 65 . The timing of the analysis period allows for a simulation of the experience of an investor nearing retirement through several market cycles, including both the depreciation and appreciation of the equities market. Of course, as with any backtest, different inputs would result in different results and so we offer this analysis as but one example. Nevertheless, we think the results of this analysis can be instructive in helping to better understand the relative utility of these two very different products from the perspective of investors in later stages of retirement planning.

Obviously, neither TDFs nor variable annuities with guarantees, as such, were yet invented in 1975. However, using the data that are readily available for the actual performance of equities and other assets during that timeframe, it is possible to arrive at a reasonable assessment of what returns would have been for typical TDFs and an investor owning the Accumulator ${ }^{\circledR}$ during that period.

Our study compared real historical data, without the use of any projections or forecasting. In each case, we assumed that the investor started with an investment of $\$ 100,000$. We further assumed that in each case, the $\$ 100,000$ invested consisted of qualified individual retirement account ("IRA") money so the tax treatment is the same. We then examined how well the respective portfolios held up, based both on their maintenance of account value and on their ability, over time, to continue to accommodate annual withdrawals from the portfolio, commencing at age 65 .

\section{Asset allocations for the comparison}

Figure 1 shows the respective asset allocations of these three approaches during the 32-year period in question.

The Accumulator ${ }^{\circledR}$ is a popular series of AXA variable annuities with global benefit offerings. In this instance, as depicted in the first (left-hand) chart in Figure 1 it utilized an aggressive asset allocation fund, with fixed allocations of 10 per cent fixed income, 30 per cent international equities and 60 per cent U.S. domestic equities. Among the 

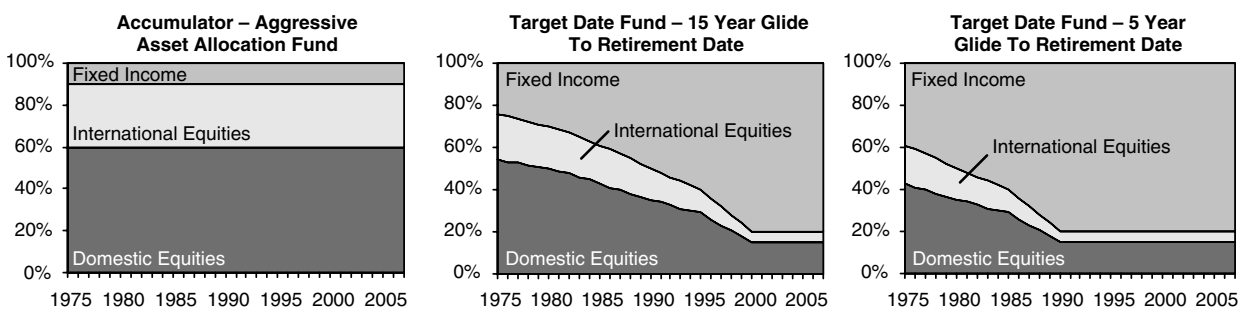

Figure 1. Asset allocations for three approaches.

more recognized Accumulator ${ }^{\circledR}$ benefits offered by AXA, are the guaranteed minimum income benefit (GMIB), guaranteed withdrawal benefit for life (GWBL) and guaranteed minimum asset benefit (GMAB). For this study, we focused on the GMIB and the GWBL, since these are currently the most popular benefits in the marketplace today. ${ }^{6}$ Both can provide a measure of downside protection that can help encourage investors to feel comfortable pursuing a more equity-oriented investment strategy, while at the same time providing a guarantee of lifetime income used to bring focus on benefits that can provide significant asset accumulation as well as the ability to withdraw meaningful income. However, the GMAB benefit should also be noted as it provides significant value to investors. This benefit offers the higher of the original principal or the account value, while guaranteeing the return of at least your original principal, adjusted for withdrawals and transfers, regardless of market performance, offering the assurance and opportunity for upside, which investors seek.

For this study, the expense ratio was calculated for the two different living benefits: the GMIB, with a total contract expense ratio of 3.21 per cent, and the GWBL, with a total contract expense ratio of 3.16 per cent. Here is a brief explanation of each of these living benefit options with some numerical examples:

- The GMIB provides a "floor" for future lifetime income that is predictable from the outset. The investment creates an income "benefit base" that is the basis for calculating the lifetime income guarantee. This "income base" grows at a 6 per cent compounded rate until age 85 , the last date the rider can be exercised. ${ }^{7}$ The client can elect either to have the benefit base grow at the 6 per cent rate, or to take the 6 per cent growth of the benefit base as an annual withdrawal from the contract and keep the benefit base level. If the account value on an annual contract anniversary is greater than the benefit base, the benefit base can be reset to the higher amount, and

\footnotetext{
${ }^{6}$ Note that product descriptions contained in this paper are of versions of products and optional riders that AXA Equitable offers as of the date of this writing. Any description is only a summary. For a complete description of the product features, benefits, fees and risks, refer to the prospectus and the Accumulator ${ }^{\circledR}$ contract and any references in this paper to such contract is qualified in its entirety by such documents. This paper is not intended for use with customers nor may be used as sales material in connection with the purchase of an Accumulator ${ }^{\mathbb{R}}$ contract or any other security, insurance or other product.

${ }^{7}$ The GMIB benefit is also available with a 6.5 per cent compounded rate and a corresponding 6.5 per cent dollar-for-dollar withdrawal strategy for a higher fee.
} 
this new benefit base will grow at the 6 per cent rate. The GMIB provides the option to invest in equities, receive a set annual withdrawal stream from the contract while maintaining liquidity, and should the account value decline to a level where the client could no longer continue to make such withdrawals (or for any other reason), allows the investor to annuitize the contract for a minimum lifetime income amount, which is determined at issuance of the contract. ${ }^{8}$

- The Accumulator ${ }^{\circledR}$ GWBL allows withdrawals to begin at a guaranteed lifetime rate of 4, 5, 6 or 7 per cent of the investment (which creates a withdrawal "benefit base"), depending on the GWBL age-band of the annuity owner when withdrawals begin (or the age-band of the younger spouse if the GWBL rider is elected with the joint life option). ${ }^{9}$ This formula provides a guaranteed lifetime minimum withdrawal amount, which can grow if investment portfolios perform well. Further, when GWBL is selected as an option, the benefit base grows by 5 per cent annually (simple interest) during the first 10 years, when no withdrawals are taken ("deferral bonus"). Additionally, for the life of the contract there is an automatic reset, or "ratchet up" of the benefit base to market value on any contract anniversary when the account value exceeds the GWBL benefit base, thereby increasing the annual withdrawals. ${ }^{10}$ The guaranteed withdrawal percentages could also be increased if a reset of the benefit base occurs while the investor(s) are in a higher age-band, resulting in increased annual withdrawals. The key to either of these living benefit options is that they provide the ability to obtain a guaranteed minimum income stream for life regardless of the performance of the underlying assets of the portfolio.

The TDF shown in the second (middle) chart of Figure 1 is a retail TDF (sold directly to an investor by the fund's broker or a financial advisor), typical of those often considered by 50 -year-olds with 15 years prior to retirement. The asset allocation in Year 1 has 54 per cent in U.S. domestic equities, 22 per cent in international equities and 24 per cent in fixed income. By Year 15, this has shifted to 35 per cent U.S. domestic equities, 15 per cent international equities and 50 per cent fixed income. For Year 25 and later, the ratio has shifted to 15 per cent U.S. domestic equities, 5 per cent international equities and 80 per cent fixed income. The expense ratio for this TDF was calculated at 1.88 per cent. ${ }^{11}$

\footnotetext{
${ }^{8}$ There is a minimum 10-year waiting period (for investors aged 50-75) between contract issue and exercising the GMIB, with a minimum exercise age of 60 , for investors aged 45 and above. Resetting the benefit base triggers a new 10-year waiting period, unless the original exercise date were later. For contracts issued or reset for investors aged 20-44, the minimum waiting period is 15 years. Additional terms and conditions may apply.

${ }^{9}$ The GWBL age-bands are 45-64, 65-74, 75-84 and 85 + years, corresponding to guaranteed withdrawal percentages of $4,5,6$ or 7 per cent of the benefit base, respectively.

${ }^{10}$ The GWBL benefit base can only be reduced due to an excess withdrawal.

${ }^{11}$ The TDF expense ratio used for this analysis is an "all-in" ratio, which includes expense at the TDF level, distribution fees, and indirect acquired fund fees and expenses to reflect the TDF "fund-of-fund" structure. This expense ratio is representative of TDFs sold in the advisor marketplace, and provides a more evenhanded comparison to variable annuities, also sold in the advisor marketplace, than would non-commission-based funds.
} 
The TDF depicted in the right-hand chart is also a retail TDF, typical of those offered to 60 -year-olds with 5 years left prior to retirement. Its Year 1 allocation was 43 per cent U.S. domestic equities, 18 per cent international equities and 39 per cent fixed income. By Year 5, this has shifted to 35 per cent U.S. domestic equities, 15 per cent international equities and 50 per cent fixed income. By Year 15 and afterwards, the allocation is 15 per cent U.S. domestic equities, 5 per cent international equities and 80 per cent fixed income. For this TDF option, the expense ratio was calculated at 1.88 per cent annually. ${ }^{8}$

In each of the three options - the variable annuity and the two TDFs - the performance of the U.S. domestic equities component of the asset allocation was based on the S\&P 500 with dividends reinvested; the international equities component on the Morgan Stanley Capital International "Europe, Australasia, and Far East," or the MSCI EAFE Index; and the fixed-income component on the Lehman Aggregate Bond Index. $^{12}$

\section{The results for a 50-year-old investor with a 15-year retirement horizon}

Let us begin our comparison of the variable annuity versus the TDF with the case of a 50 -year-old investor who invested $\$ 100,000$ in an IRA in 1975. As can be seen in Figure 2, both accounts continued to accumulate assets without withdrawals until 1990, when the investor turned 65 and began to take 6 per cent annual withdrawals, which increased over time in accordance with market appreciation or 6 per cent compounded benefit base increases resulting in the optional annual resets (should the account value on the contract anniversary exceed the benefit base) of the GMIB benefit base. ${ }^{13}$ With both the variable annuity (using the GMIB option) and the TDF, annual withdrawal amounts began at $\$ 38,211$ in 1990 ; rose to $\$ 43,670$ from 1991 to 1996; then stepped up gradually to $\$ 67,440$, where they remained from 2001 to 2007, the current year, at which point the investor turns 82 . In both cases as well, total withdrawals during the 1990-2007 period were $\$ 976,386$.

By 2007, despite the significant downturn in the stock market that had taken place from 2001 to 2003, the investor holding a variable annuity with the GMIB option still had a remaining asset value of $\$ 491,000$ in his/her account. The value of the investor's account using the TDF option, by contrast, would have shrunk to $\$ 359,000$ by 2007 slightly less than 75 per cent of the value the assets would have had with the GMIB option in place.

The difference is due to two factors: the variable annuity's upside growth opportunity due to the account's continued aggressive allocation in equities, and the lifetime income guarantees made possible by the GMIB rider.

${ }^{12}$ For the year 1975, the Lehman Aggregate Bond Index was not available. As a result, we used a proxy of 50 per cent Lehman U.S. Government Intermediate and 50 per cent Lehman U.S. Intermediate Credit.

${ }^{13}$ For the GMIB benefit, withdrawals are based solely on the GMIB benefit base. The benefit base is equal to the contributions growing at a compounded 6 per cent interest rate. If on any anniversary prior to age 76 , the account value is higher than the benefit base, the benefit base is reset to the higher amount and will grow at 6 per cent thereafter. 

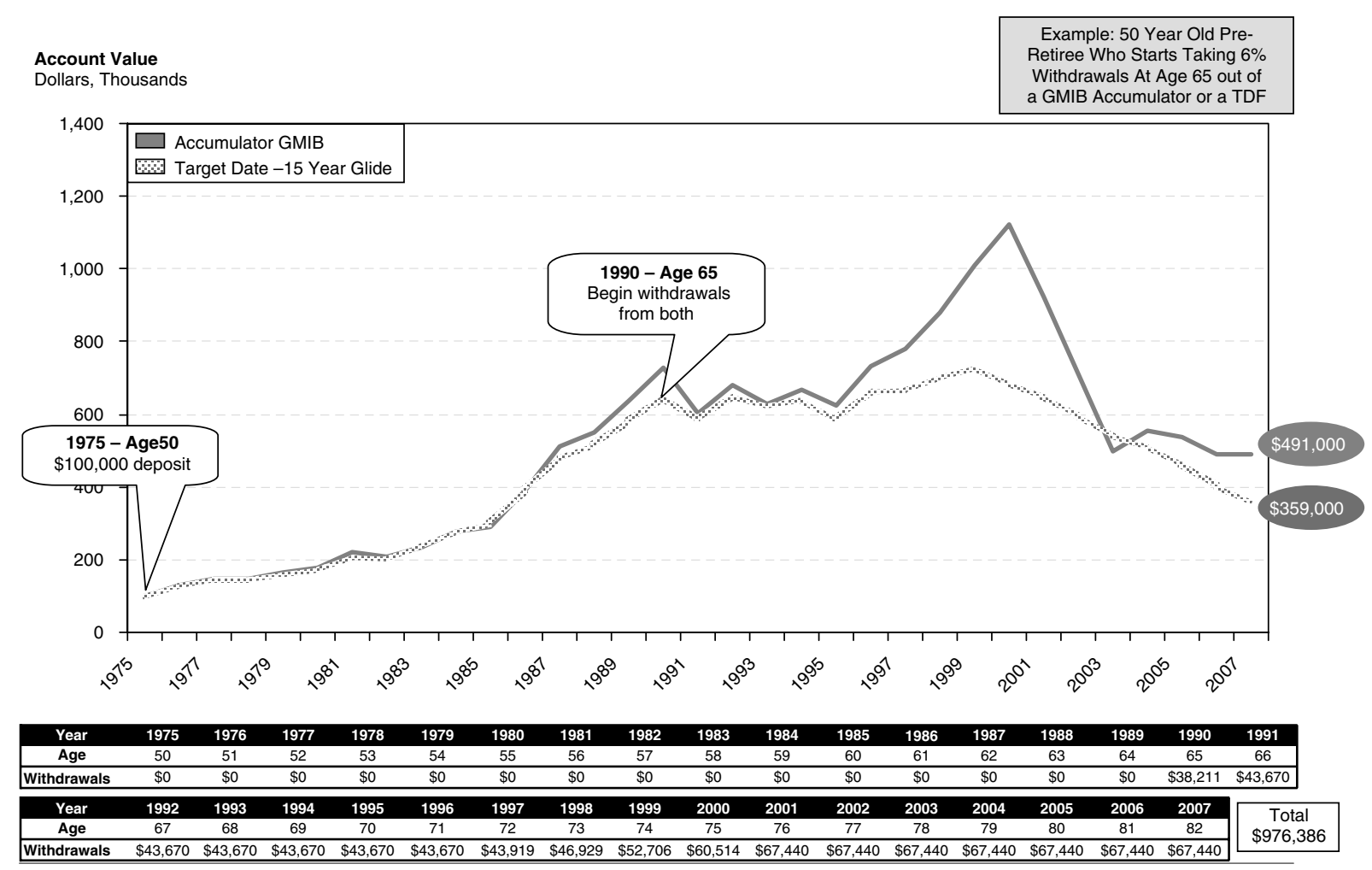

Figure 2. By age 82, the GMIB account value is nearly 1.4 times that of a target date fund \& guarantees lifetime income.

Note: In 1975, the Lehman Aggregate Index was not available. As a result, we used a proxy of 50 per cent Lehman U.S. Government intermediate and 50 per cent Lehman U.S. Intermediate Credit. 
The disparity in absolute dollars is even greater when the TDF was contrasted with the variable annuity using the GWBL option, as displayed in Figure 3.

Despite withdrawals that totaled $\$ 984,806$ between 1990 and 2007 , the variable annuity with the GWBL option still had a remaining account value of $\$ 568,000$. By contrast, the TDF had an account value of only $\$ 413,000$, a full $\$ 155,000$ less than the comparable variable annuity option. In addition, the GWBL would continue to allow annual withdrawals of $\$ 77,184^{14}$ during the remainder of the investor's lifetime, regardless of market value, whereas with the same withdrawal amount, the TDF account would run out in approximately 6 years. The annuity option therefore provided superior asset value, as well as superior guarantees of lifetime income.

\section{The results for a 60-year-old investor with a 5-year retirement horizon}

The differences in both these dimensions are even more pronounced when we compare the TDF option with a variable annuity using just a 5-year horizon before retirement. In either case, the shorter time horizon allows less time for asset accumulation prior to beginning withdrawals from the account; but in the case of the variable annuity, the living benefits enable the account to remain heavily invested in equities, with the continued ability to withdraw money annually regardless of the amount left in the account. Let us first compare a TDF with the GMIB option, as displayed in Figure 4.

Beginning with a $\$ 100,000$ deposit in 1975 , a 60-year-old investor would have experienced only modest asset accumulation before beginning to take 6 per cent annual withdrawals at age $65 .{ }^{9}$ These withdrawals would have begun with $\$ 10,031$ in 1980 , based on 6 per cent of the benefit base; and stepped up very gradually to $\$ 25,173$, based on 6 per cent of the benefit, in annual withdrawals through market appreciation and benefit base resets from 1991 to 2000 , based on 6 per cent of the benefit base, at which time the investor turns 85, the last date by which the GMIB can be exercised. By that date, a total of $\$ 410,143$ would have been withdrawn from the account, using either approach.

However, at that point, at age 85, the investor using the GMIB approach would still have an account value of $\$ 667,000$, with the option to continue the account value of $\$ 667,000$ for living expenses and/or estate planning, or to exercise the GMIB and annuitize the income base for an annual payout of $\$ 56,000$ for the remainder of his/her life. By contrast, the investor using a TDF would be left at that point with an account value of only $\$ 167,000$, which would be sufficient only through 2007 at a continued withdrawal rate of $\$ 25,173$ per year. Again, the annuity could have offered superior results with respect to asset value as well as lifetime income.

An even more dramatic difference is evident when we contrast the TDF option with a variable annuity using the GWBL rider, as displayed in Figure 5.

\footnotetext{
${ }^{14}$ For the GWBL benefit, withdrawals are based solely on the GWBL benefit base, which is initially equal to the contributions and the applicable withdrawal percentage. In each of the first 10 years with no withdrawals, the benefit base grows at a simple 5 per cent interest rate. If on any anniversary the account value is greater than the benefit base, the benefit base is reset to that higher amount.
} 


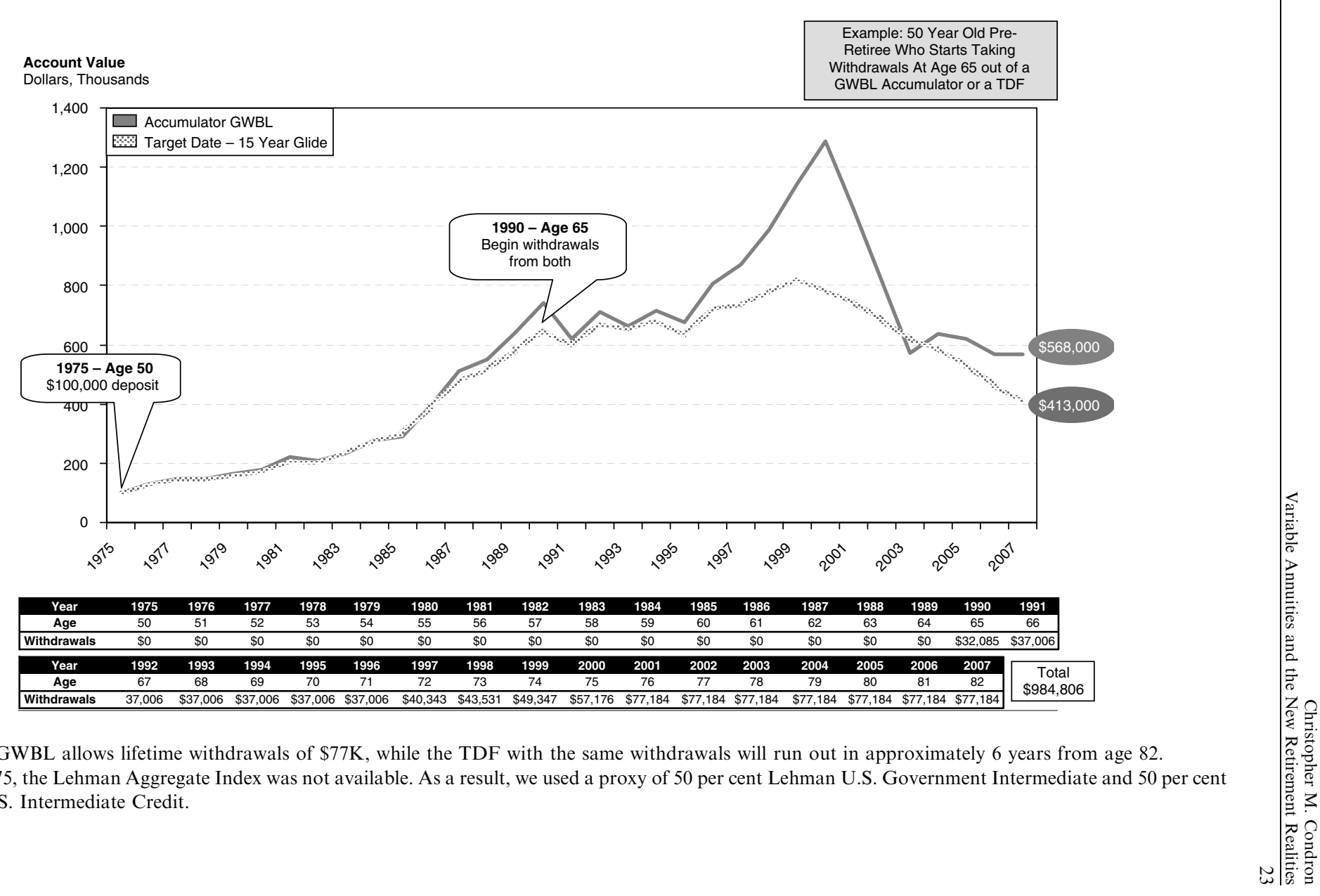

Figure 3. GWBL allows lifetime withdrawals of $\$ 77 \mathrm{~K}$, while the TDF with the same withdrawals will run out in approximately 6 years from age 82

Note: In 1975, the Lehman Aggregate Index was not available. As a result, we used a proxy of 50 per cent Lehman U.S. Government Intermediate and 50 per cent Lehman U.S. Intermediate Credit. 


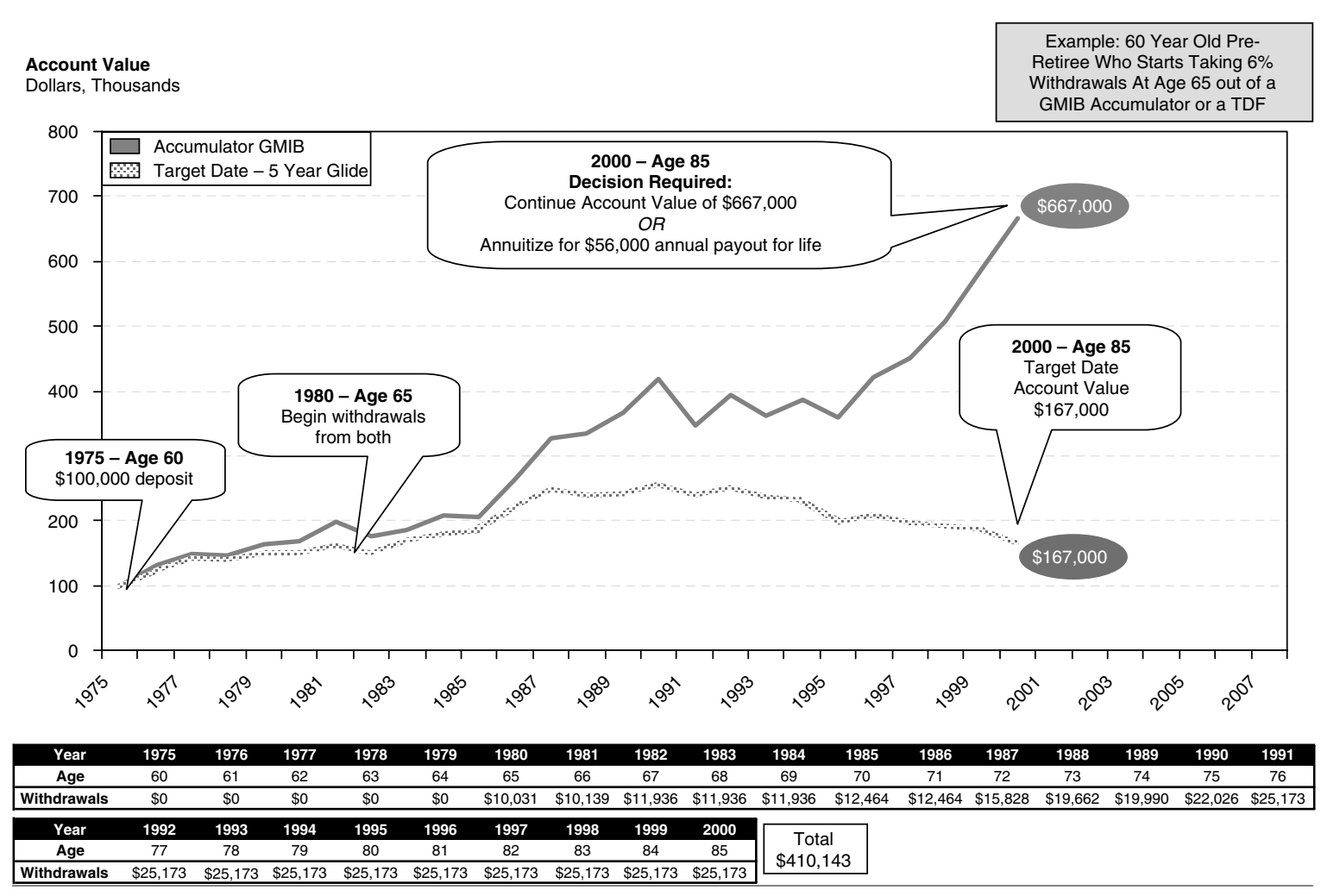

Figure 4. By age of 85 , the GMIB account value is four times that of a TDF and allows for lifetime annuity or continued contract.

Note: In 1975, the Lehman Aggregate Index was not available. As a result, we used a proxy of 50 per cent Lehman U.S. Government Intermediate and 50 per cent Lehman U.S. Intermediate Credit. 


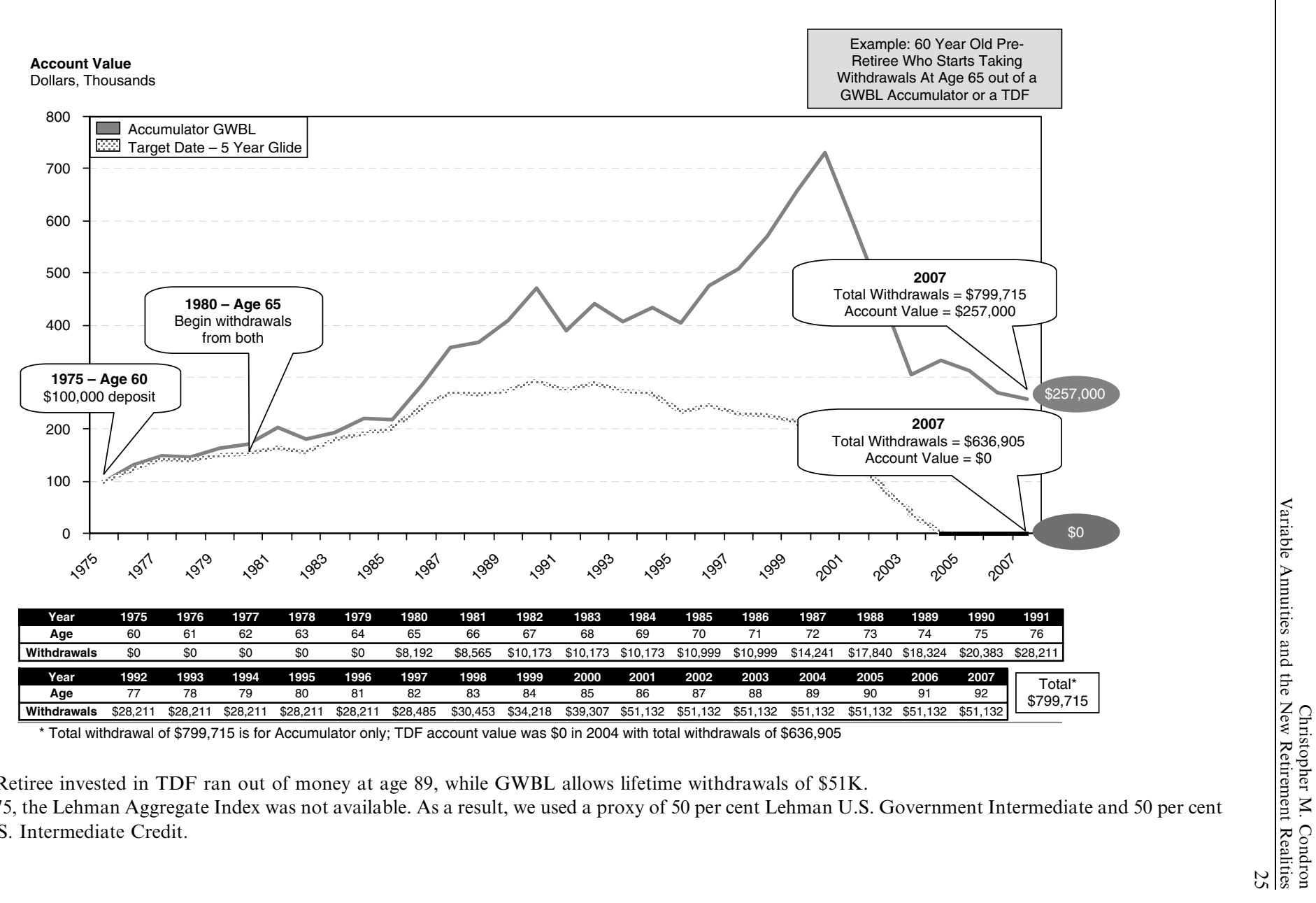

Note: In 1975, the Lehman Aggregate Index was not available. As a result, we used a proxy of 50 per cent Lehman U.S. Government Intermediate and 50 per cent Lehman U.S. Intermediate Credit. 
Commencing withdrawals in 1980 at age 65 using the GWBL option, which provides benefit base resets and withdrawal percentage increases related to age-band, the investor would begin at an annual withdrawal rate of $\$ 8,192$ and step up to $\$ 28,211$ by 1991 ; remain at that annual withdrawal level through 1996 ; then increase gradually again to a withdrawal level of $\$ 51,132$ each year commencing in 2001 , and remain at that level through 2007, which is the last date for which there is historical data. $^{10}$ Total withdrawals from 1980 through 2007, using the GWBL option, would reach $\$ 799,715$, with a remaining account value of $\$ 257,000$.

By contrast, an investor employing a TDF and withdrawing money from the account at the same rate would have run out of money by 2004 , with only $\$ 636,905$ in withdrawals in that time. No further retirement income from the account would have been possible for the investor beyond 2004 - whereas using the GWBL option, the investor would not only have $\$ 257,000$ remaining in asset value, but also would be able to continue withdrawing $\$ 51,132$ a year for the remainder of his/her lifetime, even if the account's balance were to reach zero.

\section{Comparisons using a start date of $\mathbf{1 9 7 3}$}

We also conducted a similar comparison starting with 1973, employing identical asset allocation strategies and expense assumptions as in the 1975-based scenarios. Comparing results using 1973 and 1975 start dates was important due to the market downturn that took place between those two dates. Clearly, with any investment portfolio, entry and exit points are critical and the first few years can make a significant difference in asset accumulation over time, as demonstrated by the following scenarios.

Comparing the GMIB option with the TDF option with a 15-year retirement horizon, as displayed in Figure 6, we commenced 6 per cent annual withdrawals in 1988, when the investor would have reached age 65. ${ }^{9}$ Annual withdrawals started that year at $\$ 18,881$ and then, through market appreciation and benefit base resets, gradually stepped up to $\$ 24,173$ in 1991, remaining there until 1996. They then stepped up to $\$ 29,175$ in 1999 and remained at that level until 2007.

Despite the fact that during the period from 2000 to 2003, the GMIB-based account had lost approximately half its value, the amount remaining in the GMIB option $\$ 355,000$ - was nearly equal to that of $\$ 357,000$ left in the TDF-based account, while $\$ 517,128$ had been withdrawn from each account. In addition to the equities-based rebound the GMIB account experienced after 2003, the GMIB rider would have permitted annual withdrawals after 2007 for the lifetime of the individual, compared with the relatively limited potential for equivalent withdrawals from the TDF-based account. Even if the GMIB had not experienced an equities-based rebound in 2003 and the amount remaining in the GMIB account was lower than the remaining value in the TDF-based account, the GMIB rider would still guarantee lifelong annual withdrawals after 2007.

Under the same scenario, however, the GWBL option with a 15-year time horizon, as depicted in Figure 7, permitted the holder of that account to withdraw even greater amounts, while permitting greater asset accumulation compared with the TDF option. 


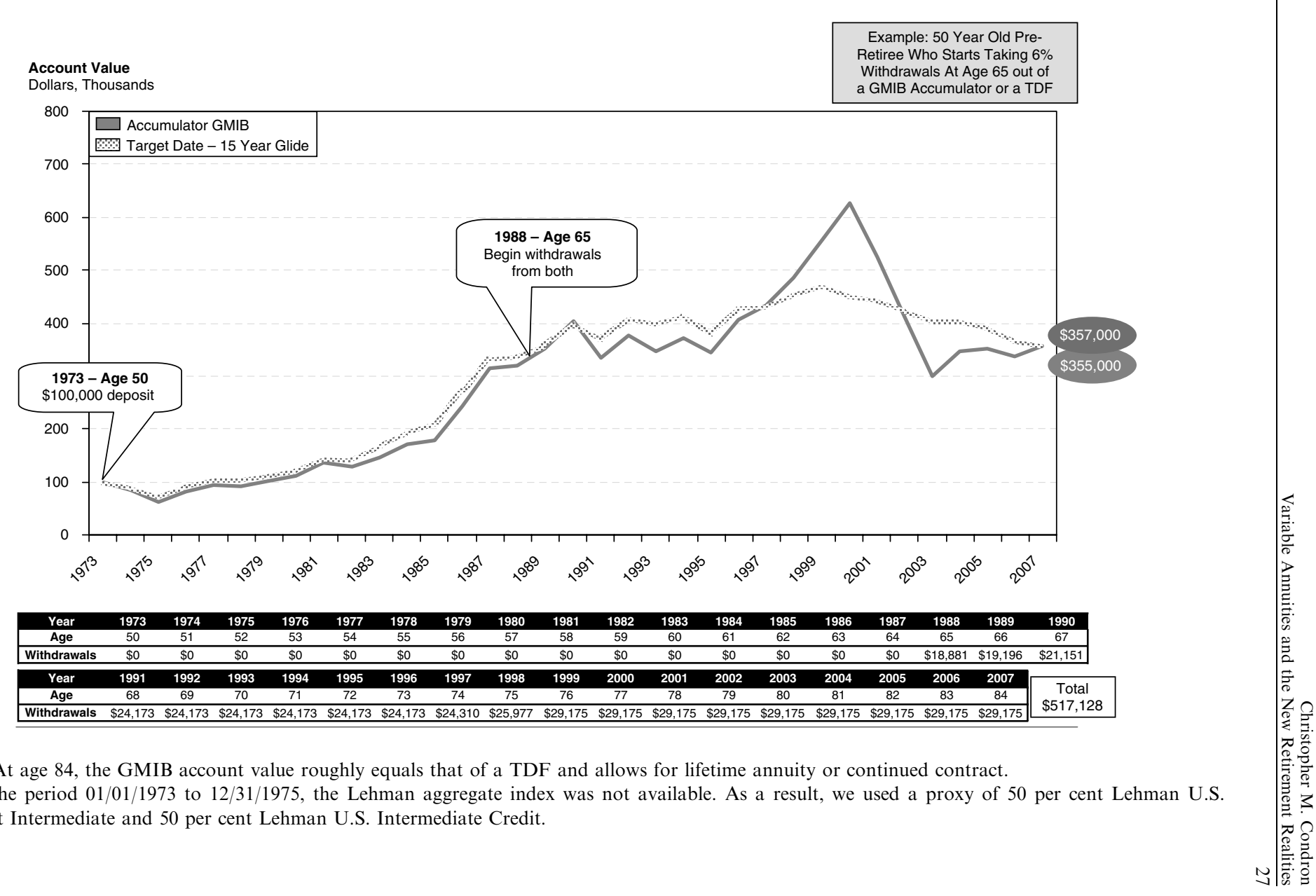

Figure 6. At age 84, the GMIB account value roughly equals that of a TDF and allows for lifetime annuity or continued contract.

Note: For the period 01/01/1973 to 12/31/1975, the Lehman aggregate index was not available. As a result, we used a proxy of 50 per cent Lehman U.S Government Intermediate and 50 per cent Lehman U.S. Intermediate Credit. 


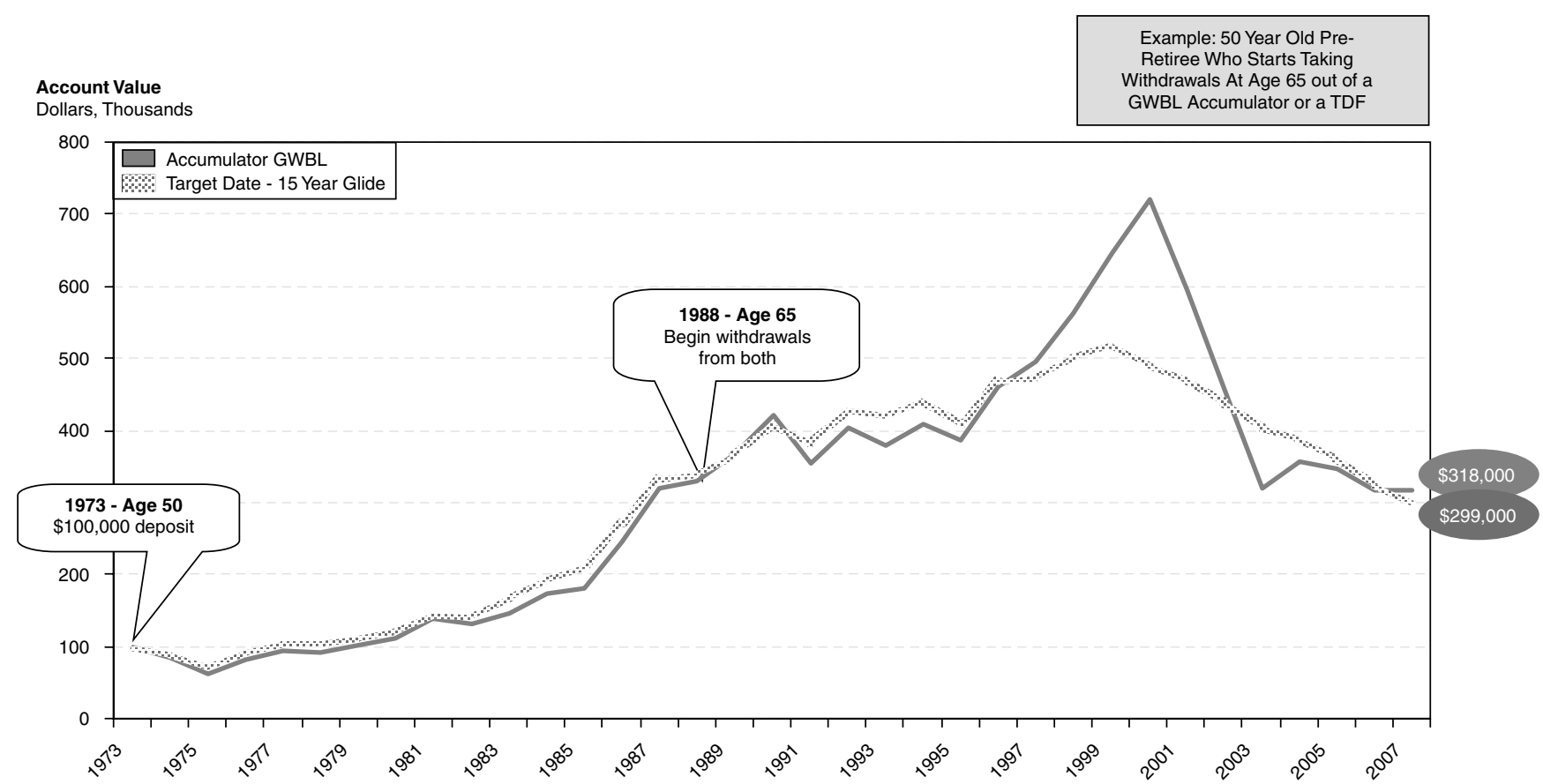

\begin{tabular}{|c|c|c|c|c|c|c|c|c|c|c|c|c|c|c|c|c|c|c|}
\hline Year & 1973 & 1974 & 1975 & 1976 & 1977 & 1978 & 1979 & 1980 & 1981 & 1982 & 1983 & 1984 & 1985 & 1986 & 1987 & 1988 & 1989 & 1990 \\
\hline Age & 50 & 51 & 52 & 53 & 54 & 55 & 56 & 57 & 58 & 59 & 60 & 61 & 62 & 63 & 64 & 65 & 66 & 67 \\
\hline Withdrawals & $\$ 0$ & $\$ 0$ & $\$ 0$ & $\$ 0$ & $\$ 0$ & $\$ 0$ & $\$ 0$ & $\$ 0$ & $\$ 0$ & $\$ 0$ & $\$ 0$ & $\$ 0$ & $\$ 0$ & $\$ 0$ & $\$ 0$ & $\$ 16,004$ & $\$ 16,438$ & $\$ 18,285$ \\
\hline Year & 1991 & 1992 & 1993 & 1994 & 1995 & 1996 & 1997 & 1998 & 1999 & 2000 & 2001 & 2002 & 2003 & 2004 & 2005 & 2006 & 2007 & \\
\hline Age & 68 & 69 & 70 & 71 & 72 & 73 & 74 & 75 & 76 & 77 & 78 & 79 & 80 & 81 & 82 & 83 & 84 & Total \\
\hline Nithdrawals & $\$ 21,089$ & $\$ 21,089$ & $\$ 21,089$ & $\$ 21,089$ & $\$ 21,089$ & $\$ 21,089$ & $\$ 22,991$ & $\$ 24,808$ & $\$ 33,747$ & $\$ 38,765$ & $\$ 43,223$ & $\$ 43,223$ & $\$ 43,223$ & $\$ 43,223$ & $\$ 43,223$ & $\$ 43,223$ & $\$ 43,223$ & $\$ 600,135$ \\
\hline
\end{tabular}

Figure 7. GWBL allows lifetime withdrawals of $\$ 43 \mathrm{~K}$, while the TDF with the same withdrawals will likely run out in approximately 7 years from age 84 . Note: For the period 01/01/1973 to 12/31/1975, the Lehman aggregate index was not available. As a result, we used a proxy of 50 per cent Lehman U.S. Government Intermediate and 50 per cent Lehman U.S. Intermediate Credit. 
Annual withdrawals from the GWBL account began at a level of $\$ 16,004$ in 1988 through market appreciation, benefit base resets, withdrawal percentage increases, stepped up to $\$ 21,089$ in 1991 and remained there until 1996 then stepped up again to $\$ 43,223$ in 2001 , and remained at that level through $2007 .{ }^{10}$ By that date, the annuity with the GWBL option had assets of $\$ 318,000$, compared with $\$ 299,000$ left in the TDF fund. At that rate, moreover, with withdrawals continuing at a rate of $\$ 43,223$ annually, the TDF fund would have run out of assets in approximately 7 years, compared with the lifetime annual withdrawal guarantee of $\$ 43,223$ associated with the GWBL account, even if the GWBL account had not experienced an equities-based rebound following the market depreciation experienced from 2001 to 2003.

When looking at a 5-year retirement time horizon from the 1973 start date, an even more significant difference exists when we compare a TDF fund with a variable annuity with a GMIB rider, as depicted in Figure 8. This time, annual 6 per cent withdrawals commenced in 1978, at age 65, at a rate of \$7,575 per year through 1987 . They then stepped up to $\$ 8,937$ per year in 1989 and remained there through 1998 , when total withdrawals for both options had reached $\$ 173,907$.

As in the preceding 1973-based examples, assets for both options dipped from 1973 to 1975; but afterwards, the GMIB option accumulated greater assets, so that by 1998 , at age 85 , the GMIB account was approximately $\$ 37,000$ greater than that of the TDF - \$260,000 versus $\$ 223,000$. Moreover, at that point, at age 85, the GMIB holder had the option either to take the account value of $\$ 260,000$, or to annuitize that amount and receive a $\$ 22,000$ annual payout for life.

And just as in the 1975-based example, the owner of a GWBL established in 1973, with a 5-year retirement horizon, enjoyed clear advantages over a TDF commencing in that same year, with equivalent assumptions. As depicted in Figure 9, withdrawals from both commenced at age 65 , in 1978 , at a rate of $\$ 6,000$, and remained at that level through 1986. After that date, through withdrawal deferral bonuses, market appreciation, and benefit base resets withdrawal percentage increases they stepped up gradually to $\$ 14,347$, where they remained from 1991 to 1996 ; then gradually stepped up again to $\$ 25,550$ in 2001 and remained at that level through $2007 .{ }^{11}$

By that time, \$432,868 had been withdrawn from each account but the amount remaining in the GWBL option - $\$ 129,000$ - was more than double that of the $\$ 63,000$ left in the TDF-based account, while continuing to provide a lifetime annual guarantee of $\$ 25,550$.

\section{Conclusion: clear value in remaining invested in equities}

In all but one of these cases, what we found was that the option to continue to heavily invest in equities via a variable annuity over time would have enabled investors to accumulate greater assets and, more importantly, to be better able to continue to withdraw meaningful income from their accounts over the extended retirement period that is increasingly typical today. In both these respects, the guarantees provided through the variable annuity option offered superior risk management and better value. This can be particularly impactful when we consider that by 2020, 3 million 


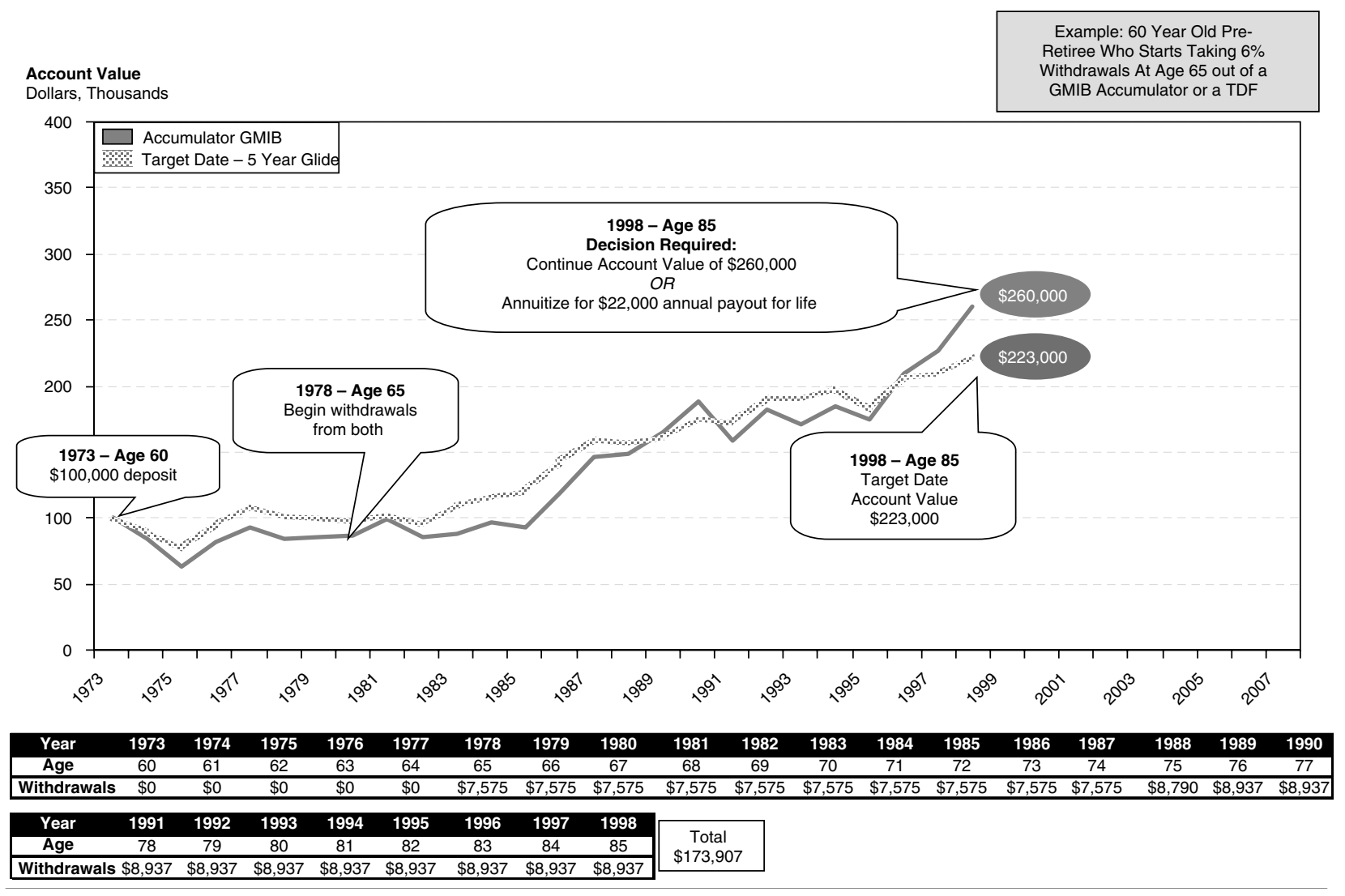

Figure 8. By age 84, the GMIB account value is greater than that of a TDF and allows for lifetime annuity or continued contract.

Note: For the period 01/01/1973 to 12/31/1975, the Lehman aggregate index was not available. As a result, we used a proxy of 50 per cent Lehman U.S.

Government Intermediate and 50 per cent Lehman U.S. Intermediate Credit. 


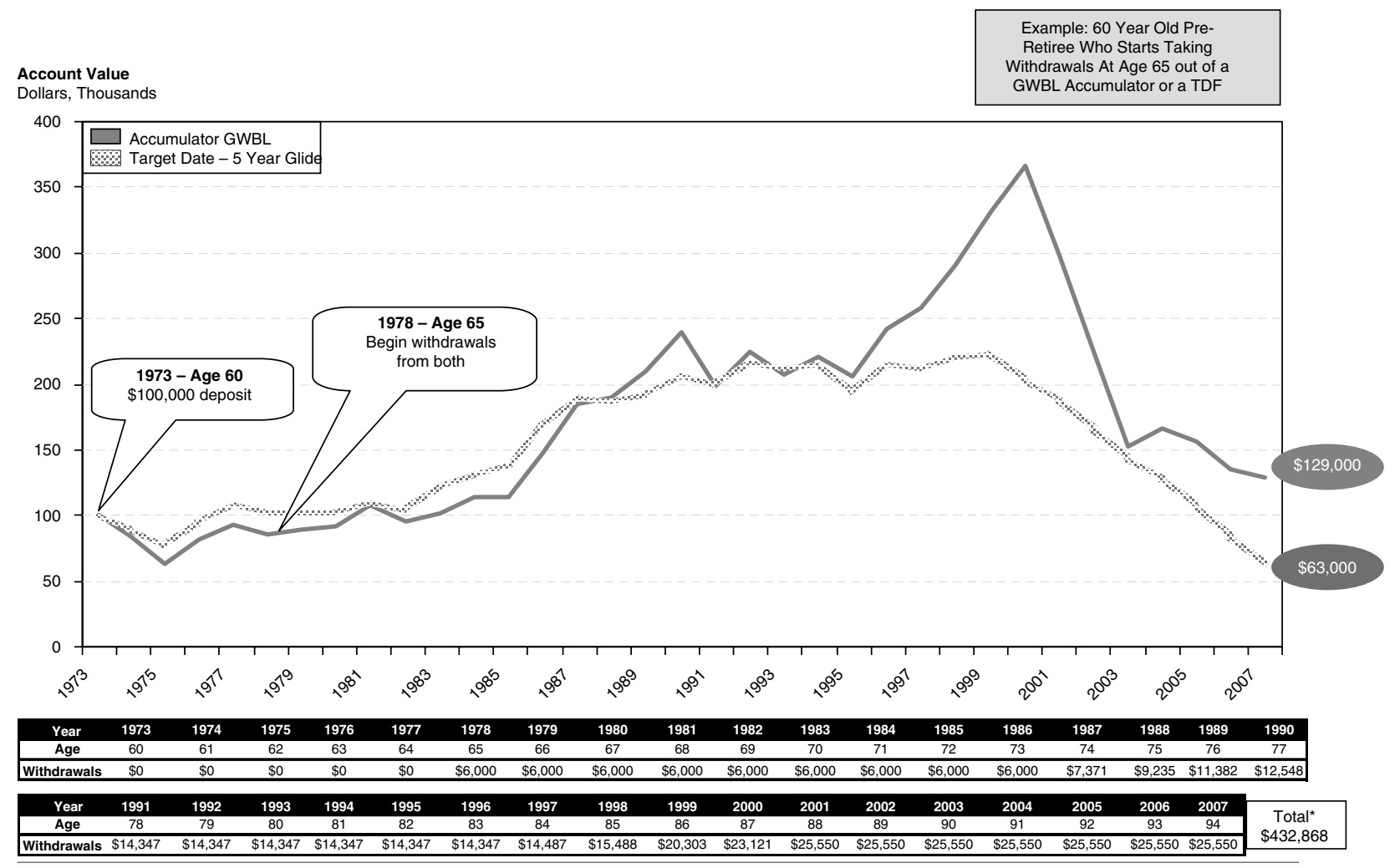

Figure 9. At age 94, the GMIB account value is twice that of a TDF and allows for lifetime withdrawals of \$26K.

Note: For the period 01/01/1973 to 12/31/1975, the Lehman aggregate index was not available. As a result, we used a proxy of 50 per cent Lehman U.S. Government Intermediate and 50 per cent Lehman U.S. Intermediate Credit. 
Americans will be in the 85-99-year old age group, with 300,000 Americans in the 100 years and older age group. ${ }^{15}$

Certainly, when one considers the highly individual nature of retirement planning, there is no "one-size-fits-all" approach. Variable annuities, by themselves, are not invariably suited to be the sole component of any investor's portfolio, and TDFs can certainly play a role in enabling investors to meet their retirement savings goals. However, the results of this study underscore that, as insurers, we need to educate individual investors about how the newer variable annuity product designs can help pre-retirees and retirees who need to do so to continue to maintain their investments in equities.

\section{References}

AXA Equitable (2007) 'AXA Equitable Retirement Scope 2007', from http://www.axaonline.com/ axaImages/AXA_Retirement_Scope_2007.pdf, accessed 10 October 2007.

Cherry, H. (1971) 'The 1971 individual annuity mortality table', Transactions of Society of Actuaries 23: 475-568.

Johansen, R. (1995-1996) ‘Annuity 2000 mortality tables', Transactions of Society of Actuaries 47: 263-290.

Munnel, A.H., Webb, A. and Golub-Sass, F. (2007) 'Is there really a retirement savings crisis? an NRRI analysis?', Center for Retirement Research, Boston College, Brief No. 7-11 (August).

United States Census Bureau (1993) Population Projections of the Unites States, by Age, Race and Hispanic Origin, 1993-2050, Washington, DC: United States Census Bureau, pp. 25-1104.

\section{About the Author}

Christopher M. "Kip" Condron is President and Chief Executive Officer of AXA Financial, Inc., a member of the AXA Group Management Board and Chairman, President and CEO of AXA Equitable Life Insurance Company. Mr. Condron served as CEO of The Dreyfus Corporation, a leading asset management company and as Co-President of AYCO Corporation, the financial and tax planning subsidiary of American Express. He founded the financial planning firm Condron Associates, which was acquired by American Express.

\footnotetext{
${ }^{15}$ United States Census Bureau (1993).
} 